\title{
Initiation and execution mechanisms of necroptosis: an overview
}

\author{
Sasker Grootjans $\mathbf{s}^{1,2}$ Tom Vanden Berghe $\mathrm{e}^{1,2}$ and Peter Vandenabeele ${ }^{\star, 1,2}$
}

Necroptosis is a form of regulated cell death, which is induced by ligand binding to TNF family death domain receptors, pattern recognizing receptors and virus sensors. The common feature of these receptor systems is the implication of proteins, which contain a receptor interaction protein kinase (RIPK) homology interaction motif (RHIM) mediating recruitment and activation of receptor-interacting protein kinase 3 (RIPK3), which ultimately activates the necroptosis executioner mixed lineage kinase domainlike (MLKL). In case of the TNF family members, the initiator is the survival- and cell death-regulating RIPK1 kinase, in the case of Toll-like receptor 3/4 (TLR3/4), a RHIM-containing adaptor, called TRIF, while in the case of Z-DNA-binding protein ZBP1/DAl, the cytosolic viral sensor itself contains a RHIM domain. In this review, we discuss the different protein complexes that serve as nucleation platforms for necroptosis and the mechanism of execution of necroptosis. Transgenic models (knockout, kinase-dead knock-in) and pharmacologic inhibition indicate that RIPK1, RIPK3 or MLKL are implicated in many inflammatory, degenerative and infectious diseases. However, the conclusion of necroptosis being solely involved in the etiology of diseases is blurred by the pleiotropic roles of RIPK1 and RIPK3 in other cellular processes such as apoptosis and inflammasome activation.

Cell Death and Differentiation (2017) 24, 1184-1195; doi:10.1038/cdd.2017.65; published online 12 May 2017

\section{Facts}

Receptor-interacting proteins (RIPK1) exist in two major forms: as a 'closed conformation', that is, kinase-deficient, and activates NF- $\kappa \mathrm{B}$ and MAPK pathways, and as an 'open conformation', that is, kinase-active, and initiates apoptosis and necroptosis.

The open kinase-active form of RIPK1 recruits and activates RIPK3 through homotypic interaction involving the RHIM domain.

RIPK3 can also be activated through the interaction with $\mathrm{RHIM}$ domain-containing adaptor TRIF or sensor ZBP1/DAI.

RIPK3 recruits and phosphorylates the pseudokinase MLKL, which represents the executioner of the necroptotic pathway. Transgenic models (knockout, kinase-dead knock-in) and pharmacologic inhibition indicate that RIPK1, RIPK3 or MLKL are implicated in many inflammatory, degenerative and infectious diseases.

\section{Open Questions}

- Can RHIM-mediated interactions be targeted for therapeutic purposes?

- What are the functions of RIPK3 and MLKL beyond necroptosis and how are they differentially regulated?

- Is MLKL the only substrate of RIPK3 involved in the execution of necroptosis?

- Is necroptosis as such the sole initiator of inflammation?
Cell death is an essential part of homeostasis in multicellular organisms as a way of removing damaged, infected or degenerated cells. ${ }^{1}$ Cell death is also a crucial factor in sculpting our bodies. ${ }^{2}$ In adults, every day about $10-100$ billion cells die and are replaced by new healthy cells to maintain homeostasis of the whole organism. ${ }^{3}$ Hence, it is no surprise that disruption of this delicate balance between cell death and cell proliferation results in disease. Indeed, resistance to cell death is one of the hallmarks of cancer cells, ${ }^{4}$ and it is well established that several viruses actively prevent the suicide of their host cell to ensure viral replication. ${ }^{5}$ On the other hand, too much cell death results in impaired organ function as is illustrated by heart- and brain infarct, or alcohol- or druginduced liver injury. ${ }^{6}$ Historically, three morphologically distinct types of cell death were observed by Schweichel and Merker ${ }^{7}$ in embryonic tissues exposed to toxic drugs and were categorized based on phagocytic clearance (type I-III). ${ }^{8}$ Type I cell death was associated with heterophagy, while type II cell death featured autophagy and type III dead cells were not removed by hetero/autophagy. ${ }^{7,8}$ On the basis of the occurrence of type I cell death in healthy tissues and during embryonic development, it was proposed that type I cell death was controlled and hence termed 'apoptosis*' by Kerr et al. ${ }^{9}$ (apoptosis = 'falling off' of leaves from a tree). Apoptotic cell death morphology is characterized by shrinkage of both nucleus (pyknosis) and cytoplasm, chromatin condensation (karyorhexis), nuclear fragmentation, and the formation of apoptotic bodies. Intact apoptotic dying cells and apoptotic

${ }^{1}$ Molecular Signaling and Cell Death unit, VIB Inflammation Research Center, 9000 Ghent, Belgium and ${ }^{2}$ Department of Biomedical Molecular Biology, Ghent University, 9000 Ghent, Belgium

${ }^{*}$ Corresponding author: P Vandenabeele, Department of Biomedical Molecular Biology, VIB-UGent Center for Inflammation Research/UGent, VIB-Ghent University, VIBUGent Research Building FSVM, Technologiepark 927, 9052 Ghent, Belgium. Tel: +32 9331 37 10; Fax: +32 9221 76 73; E-mail: Peter.Vandenabeele@ irc.vib-ugent.be Received 23.1.17; Received 23.3.17; accepted 30.3.17; Edited by M Gyrd-Hansen; published online 12.5.17 
bodies are recognized and phagocytosed by surrounding cells. $^{9}$ Type II cell death features extensive intracellular phagosome formation, retrospectively interpreted as autophagic digestion of cytosolic contents and organelles, and therefore referred to as autophagic cell death. ${ }^{8}$ However, it is better to call it cell death associated with autophagy, since autophagy does not contribute to the cell death process. ${ }^{10}$ Type III cell death, currently known as necrosis, is characterized by cellular rounding and swelling, increased cytoplasmic granularity, intact nuclei, and finally, membrane rupture and expulsion of cellular contents in a balloon-like morphology. ${ }^{11}$ Originally, it was proposed by Kerr et al. ${ }^{9}$ that only apoptosis was genetically regulated, and that necrotic cell death was the result of irreversible damage. Research in Caenorhabditis elegans led to the discovery of the genetic program of apoptotic cell death that was confirmed and elaborated in biochemical details in vertebrates. ${ }^{12,13}$

However, a pioneering publication in 1988 indicated that tumor necrosis factor (TNF) can induce both apoptotic and necrotic cell death depending on the cell line. ${ }^{14}$ Nowadays, it is clear that this necrotic cell death can be blocked by chemical inhibition, knockdown or knockout of specific genes, proving that necrosis can be regulated. ${ }^{15-19}$ The most studied subtype of regulated necrosis is TNF-induced necroptosis, which depends on RIPK1, RIPK3 and mixed lineage kinase domain-like (MLKL). ${ }^{15-18}$ Besides necroptosis, other types of regulated necrosis include caspase-1 and gasdermin D-dependent pyroptosis, ${ }^{20}$ poly-(ADP ribose)-polymerase (PARP)-dependent parthanatos, ${ }^{21}$ iron-dependent ferroptosis, ${ }^{22}$ and NADPH oxidase (NOX2)-mediated NETosis (neutrophil extracellular trap). ${ }^{23}$ Even secondary necrosis, which occurs when apoptotic cells are not removed by phagocytosis, appears to be regulated. In this case, proteolytic cleavage of deafness-associated tumor supressor (DFNA5) by caspase-3 triggers secondary necrosis. ${ }^{24}$ Figure 1 gives an overview of different types of regulated cell death, and of the core pathways involved in the initiation and execution of cell death. In the following sections, we outline the occurrence of necroptosis in embryonic development, homeostasis and disease, as a prelude to an overview of necroptotic signaling.

\section{Biological Relevance of Necroptosis}

The biological relevance of necrosis (and more specifically necroptosis) appears to be mainly related to diseases. Indeed, while apoptosis clearly occurs during embryonic development as a vital process sculpting body shape ${ }^{25}$ and regulating cell populations, ${ }^{9}$ there are only a few indications that necrosis as a cell death process actually occurs during embryonic development and under physiological conditions. These are discussed below, followed by an overview of the implication of necroptosis in disease.

Necrosis occurring under physiological conditions. Examples of necrosis during embryonic development have been observed in worms and chick embryos. During the development of $C$. elegans, the Linker cell helps to shape the gonads in male worms and then dies with a necrotic morphology. ${ }^{26}$ During normal embryonic development of chicks, necrotic morphology of developing ciliary ganglia and motor neurons of the spinal cord is observed. ${ }^{27,28}$ Another peculiar example of the occurrence of necrosis is found during development in pigs where the embryonic sacs in pigs show a necrotic cell morphology at the tips (necrotic apex) from halfway during pregnancy until birth, arguing for the occurrence of necrotic cell death under physiological conditions long before birth and expulsion of the placenta. ${ }^{29}$ Of note, it cannot be excluded that these processes are due to secondary necrosis, occurring after an unnoticed apoptotic stage. Nonetheless, there have been a few reports describing the ability of the organism to bypass apoptosis by necrotic cell death when caspase activation is affected or absent. Indeed, mice deficient for apoptotic peptidase activating factor 1 (Apaf1) or where caspase activity is blocked, the interdigital webs of mouse embryos are removed by necrotic cell death instead of apoptosis, ${ }^{30,31}$ eventually resulting in the same limb morphology. Similarly, programmed cell death of spinal motor neurons in caspase-3 or caspase-9-deficient mice is delayed as compared to wild-type mice and displays typical necrotic features. ${ }^{32}$

Altogether, it appears that necrosis during animal embryonic development only occurs sporadically and in rare instances, or as a backup method when apoptosis is impaired. In the context of this review on necroptosis signaling, it is important to mention that there is no information available on whether necrosis occurring during normal embryogenesis and physiological processes can be attributed to necroptosis. However, since neither the kinase-dead RIPK1 knock-in mice, ${ }^{33}$ nor the $\mathrm{RIPK}^{34}$ or $\mathrm{MLKL}^{35}$ knockout mice do have a spontaneous phenotype under non-challenged conditions, this strongly suggests that the core necroptotic pathway is mainly implicated in pathophysiological conditions of infection and disease.

Necroptosis in disease. In cells, necroptosis can be initiated by a variety of triggers, including TNF, Fas, TNFrelated apoptosis-inducing ligand (TRAIL), interferon (IFN), lippopolysaccharide, dsRNA, DNA damage, endoplasmatic reticulum stress, viral infection and anti-cancer drugs. ${ }^{36-44}$ Necrotic tissues in vivo have been described in the context of disease, such as gangrene, as early as the fifth century BC (Galen. On the constitution of the art of medicine; The art of medicine; A method of medicine to Glaucon). Indeed, long before the morphological definition of apoptosis, necrotic cells were linked to pathological conditions, such as alcohol abuse. $^{9}$ The first proof that at least some of this diseaseassociated necrosis could be attributed to necroptosis, came with the discovery of necrostatin-1 (Nec-1), ${ }^{15}$ the first inhibitor of RIPK1. ${ }^{45}$ It was shown that administration of Nec-1 could reduce cell death and/or mortality in several disease models, including brain infarct, ${ }^{15}$ cardiac infarct, ${ }^{46,47}$ TNF-induced systemic inflammatory respiratory syndrome (SIRS), ${ }^{48}$ ConAor acetaminophen-induced hepatitis, ${ }^{39,49}$ and ischemiareperfusion injury (IRI) in kidneys. ${ }^{50}$

However, Nec-1 was used at varying concentrations in these studies, which complicates their interpretation considering more recent findings. Indeed, $\mathrm{Nec}-1$ is identical to methylthiohydantoin-tryptophan (MTH-Trp), ${ }^{51}$ a known inhibitor of indoleamine 2,3-dioxygenase (IDO), an important immuneregulatory enzyme. At low concentrations $(0.6 \mathrm{mg} / \mathrm{kg})$, Nec-1 can potentiate TNF-induced SIRS $^{52}$ and cerulein-induced 


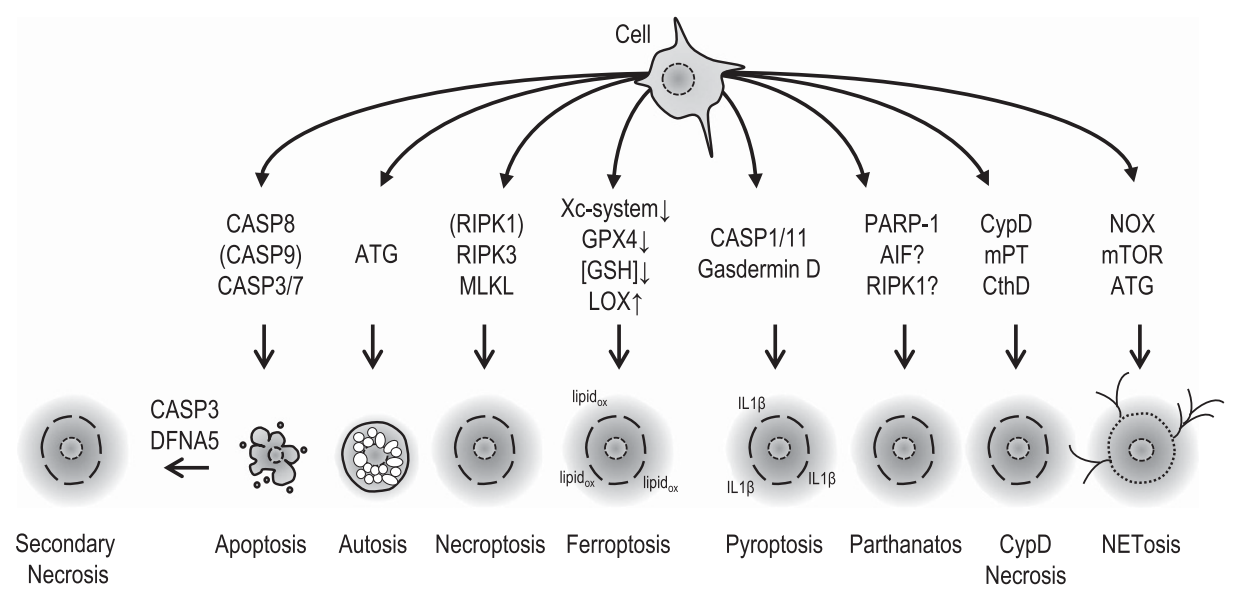

Figure 1 An overview of regulated cell death modalities and the core pathway proteins involved. Depending on cell type and intra/extracellular conditions, cells can activate different cell death modalities with different core pathway proteins involved. Cell death modalities with an apoptotic or an autophagic morphology are considered to be less immunogenic than cell death with a necrotic morphology, because the former two are consisting of containment programs aimed at preventing the release of intracellular content and associated with efficient phagocytosis, while necrotic cell death is essentially associated with membrane permeabilization resulting the rapid release of the cellular contents in the environment acting as danger or damage-associated molecular patterns (represented by a gray halo) and attracting immune cells. Note that in many conditions, induction of autophagy is not associated with cell death, but rather a homeostasis mechanism following cellular stress. However, in some conditions, autophagy may proceed to cell death and targeting Atg genes will retard in such cases the cell death process. AIF, apoptosis-inducing factor; ATG, autophagy related; CASP, caspase; CypD, cyclophillin D; DFNA5,

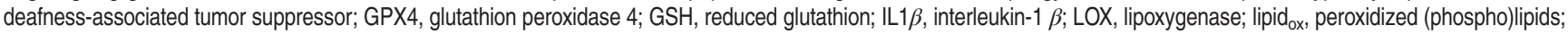
MLKL, mixed lineage kinase domain-like; mPT, mitochondrial permeability transition pore; mTOR, mechanistic target of rapamycin; NOX, NADPH oxidase; PARP, poly-(ADP ribose)-polymerase; RIPK, receptor-interacting protein kinase; Xc-system, cystin/glutamate antiporter

pancreatitis in mice. ${ }^{52,53}$ Given that Nec-1 can inhibit IDO in vitro, this contra-intuitive observation could be due to inhibition of IDO, or perhaps due to other yet unknown offtarget effects. Hence, the data obtained by Nec-1 administration may complicate the interpretation of the in vivo results in those experimental disease models where IDO has been implicated such as inflammation-associated tumorigenesis. ${ }^{54}$ Therefore, the initial findings established with $\mathrm{Nec}-1$ should be challenged with experimental disease models using RIPK1 kinase-dead knock-in mice and RIPK3 knockout mice. $\mathrm{RIPK}^{-1-}$ mice show a prolonged survival upon IRI in kidneys, ${ }^{55}$ TNF-induced SIRS ${ }^{48,56}$ and cerulein-induced pancreatitis. ${ }^{18,53}$ Furthermore, RIPK3 ablation resulted in severely delayed mortality caused by atherosclerotic plaques in apolipoprotein E (ApoE) knockout mice. ${ }^{57} \mathrm{RIPK}^{-/-}$mice are also protected from poly(I:C)-induced necrosis in the retina, ${ }^{58}$ and have reduced liver damage caused by alcohol. ${ }^{59}$ As is in all these studies, RIPK3 is lacking entirely both as a scaffold and as a kinase, and the observed protective effect of RIPK3 ablation might in theory be attributed to RIPK3 either function or both. It should be said that many studies at the beginning of the availability of RIPK3 knockout mice were rather necroptosis biased. An interesting systematic study comparing RIPK1 kinase-dead knock-in mice, RIPK3 knockout and MLKL knockout in different models of inflammation and tissue injury ${ }^{60}$ revealed that loss of RIPK3 had no effect on lipopolysaccharide-induced sepsis, dextran sodium sulfateinduced colitis, cerulein-induced pancreatitis, hypoxia-induced cerebral edema or the major cerebral artery occlusion stroke model. ${ }^{60}$ This suggests that previous studies with $\mathrm{Nec}-1$, which intended to reveal a role for necroptosis probably revealed the multiple targeting effects of $\mathrm{Nec}-1$ such as apoptosis and IDO. Catalytically inactive RIPK1 knock-in mice showed reduced renal IRI and TNF-induced SIRS, while similar protection was only received in case when RIPK3 or MLKL were combined with caspase-8 knockout, suggesting a role for RIPK1 kinase activity in both necroptosis and apoptosis. ${ }^{60}$ Interestingly, one study revealed an enhanced sensitivity of RIPK3 knockout mice in a model of DSS-colitis, suggesting that RIPK3 may also have tissue regenerative functions. ${ }^{61}$

Necroptosis can also be beneficial in certain pathological settings: it is known that cellular suicide can prevent the completion of pathogen replication cycles, and thus prevent disease progression. This is for instance the case for vaccinia infection and murine cytomegalovirus (MCMV) infection. Indeed, RIPK3 ${ }^{-1-}$ mice and RIPK1-D138N kinase-dead knock-in mice show less tissue damage during vaccinia infection, but suffer from increased viral titers and die after vaccinia infection, unlike their wild-type littermates. ${ }^{37,62}$ In the case of MCMV, its M45 protein blocks necroptosis of the host cell by disturbing RIPK homotypic interaction motif (RHIM)dependent interactions of the necrosome.$^{63}$ It was shown that MCMV strains with a mutated RHIM domain in M45 fail to replicate in cells and in vivo. ${ }^{64}$ In RIPK3 ${ }^{-1-}$ mice however, the M45-mutant MCMV replicates like the wild-type strain, which indicates that RIPK3-dependent necroptosis prevents MCMV replication. ${ }^{64}$ Other viruses such as herpes simplex virus 1 and 2 appear to contain similar RHIM-proteins. ${ }^{65}$ Recently, it was discovered that during infection of its host, Escherichia coli injects the cysteine protease EspL, which is able to cleave the RHIM domain of all known RHIM-containing proteins. ${ }^{66}$ Interestingly, ectopic expression of EspL prevented TNF- or poly(l:C)-induced necroptosis in cells, while EspL protease activity contributes to persistent colonization of mice by the bacterial entheropathogen Citrobacter rodentium. ${ }^{66}$ These findings indicate that necroptosis may have an anti-infectious function by preventing specific viral and bacterial infections, or even contribute to tissue generation. ${ }^{61}$ 
Table 1 Overview of studies linking necroptosis to human pathologies

\begin{tabular}{|c|c|c|}
\hline Disease & Major finding & Reference \\
\hline Ovarian cancer & Low MLKL expression associated with poor prognosis & 138 \\
\hline Inflammatory bowel disease & High RIPK3 and MLKL expression & 139 \\
\hline Drug-induced liver injury & Phosphorylated MLKL in biopsies & 99 \\
\hline $\begin{array}{l}\text { Chronic obstructive pulmonary } \\
\text { disease }\end{array}$ & Increased levels of RIPK3 in lung epithelial cells & 140 \\
\hline Multiple sclerosis & Increased levels of RIPK1, RIPK3 and necrosome formation in lesions & 141 \\
\hline Breast cancer & Low RIPK3 expression due to epigenetic modification & 142 \\
\hline Melanoma & $\begin{array}{l}\text { Melanoma cell lines lack RIPK3 expression, whereas primary melanocytes strongly } \\
\text { express RIPK3. }\end{array}$ & 143 \\
\hline HIV & $\begin{array}{l}\text { Dysfunctional HIV-specific CD8 }{ }^{+} \text {T-cell proliferation is associated with increased caspase- } 8 \\
\text { activity and mediated by necroptosis. }\end{array}$ & 144 \\
\hline Colon cancer & Low expression of RIPK1 and RIPK3 due to hypoxia & 145 \\
\hline Small cell lung carcinoma & Loss of RIPK3 expression due to epigenetic modification & 146 \\
\hline Non-Hodgkin lymphoma & SNPS in the RIPK3 are correlated with increased risk of non-Hodgkin lymphoma & 147 \\
\hline Pancreatic adenocarcinoma & Low expression of MLKL & 148 \\
\hline Gastric cancer & Low MLKL expression associated with poor prognosis & 149 \\
\hline Cervical squamous cell carcinoma & Low MLKL expression associated with poor prognosis & 150 \\
\hline Toxic epidermal necrolysis & Phosphorylated MLKL in biopsies & 151 \\
\hline Leukemia & RIPK3 is downregulated & 152 \\
\hline
\end{tabular}

An additional complication is that RIPK1, RIPK3, MLKL, Fas associated via DD (FADD) and caspase-8 may have additional functions besides cell death. Indeed, several studies have shown that under particular conditions (caspase-8 inhibition or IAP inhibition), RIPK3 and MLKL can also activate inflammasomes, thus promoting IL1 $\beta$ maturation and tissue inflammation $^{67-70}$ (and reviewed in refs 7172 ). In contrast to the inflammation associated with massive (necroptotic) cell death, recent studies hint that moderate and chronic necroptosis may perhaps serve to dampen an inflammatory response. Indeed, in caspase-8-deficient mice, RIPK3 loss provided greater protection to TNF-induced SIRS compared to MLKL deficiency. ${ }^{60}$ This could mean that MLKL shuts down the pro-inflammatory signaling emerging from RIPK1 and RIPK3 by inducing necroptotic cell death, a notion supported by other studies. ${ }^{73,74}$ Furthermore, RIPK1, RIPK3 and MLKL may have unknown functions in the nucleus as they translocate to the nucleus early during necroptosis. ${ }^{75}$ In this context, it is interesting that nuclear proteins involved in mRNA splicing were found to interact with RIPK3 during necroptosis ${ }^{18,76}$ and that several proteins involved in the cell cycle were reported to interact with RIPK $1,{ }^{77}$ RIPK3 $^{76}$ and $\mathrm{MLKL}^{78}$ (summarized in Supplementary Table 1).

In conclusion, targeting RIPK1, RIPK3 or MLKL, could be beneficial in several inflammatory and degenerative diseases. Inhibition of RIPK1 or RIPK3 has proven to improve the outcome of a long list of pathological mouse models, including IRI in brain, $^{15}$ heart ${ }^{46,47}$ and kidney, ${ }^{50}$ SIRS, ${ }^{48,56,79}$ atherosclerosis, ${ }^{57}$ pancreatitis, $^{18,53}$ hepatitis $^{39,49}$ and liver damage. ${ }^{49,59}$ It is now understood that not only necroptosis is targeted in such settings, but also RIPK1 kinase-mediated apoptosis. Moreover, due to the pleiotropy of RIPK3 in regulating other processes such as inflammasome activation, ${ }^{67-70}$ apoptosis $^{56}$ and intestinal tissue regeneration, ${ }^{61}$ it is not clear whether necroptosis is the only cell death modality or process implicated in these pathologies. Of note, necroptosis is not always a detrimental process: in some pathologies, it may be beneficial to boost necroptosis. This may be the case when apoptosis cannot be activated due to absence of FADD or caspase-8 in cancer cells or in virally infected cells. ${ }^{37,42,44}$ Hence, a better understanding of the molecular signaling mechanisms that result in necroptosis and of the pleiotropy of the molecules involved, is guaranteed to have therapeutic implications. Indeed, necroptosis has been identified in several human pathologies (summarized in Table 1).

\section{Necroptosis Signaling}

In the following section, the three main proteins directly involved in necroptotic signaling are introduced, viz. RIPK1, RIPK3 and MLKL, and discussed in the context of the canonical and non-canonical necrosome formation.

Individual proteins and their domain structure. Receptorinteracting protein 1 (RIPK1) was the first protein shown to be essential for Fas, TNF- and TRAIL-induced necroptosis. RIPK1 kinase activity was required for these processes. ${ }^{36}$ RIPK1 is an integrator of cellular stress signals and possesses several domains that can activate different cellular pathways: an N-terminal kinase domain, an intermediary domain (ID) and a C-terminal RHIM, and death domain (DD, Figure 2).$^{80}$ Its $\mathrm{N}$-terminal kinase domain is required for canonical necroptosis, ${ }^{36,81,82}$ but also for RIPK1-dependent apoptosis under specific conditions. ${ }^{83,84}$ The C-terminal death domain of RIPK1 is involved in activation of apoptosis by recruitment of FADD and caspase- $8 .^{85,86}$ The ID of RIPK1 serves as a scaffold for $\mathrm{K} 63$ and linear M1 ubiquitylation allowing the recruitment of the TGF $\beta$ activated kinase 1 (TAK1) complex and the $I_{\kappa} B$ kinase $(\mathrm{IKK})$ complex. This results in activation of ERK, JNK, p38 and the nuclear factor $\kappa \mathrm{B}(\mathrm{NF}-\kappa \mathrm{B}){ }^{8,81}$ Furthermore, RIPK1 possesses a RHIM domain located at the C-terminal part of the ID, which is required for recruitment of RIPK3 and for binding to other $\mathrm{RHIM}$-containing proteins, such as TRIF, (Toll/IL-1R domaincontaining adapter-inducing IFN- $\beta$, also known as TICAM1) and Z-DNA-binding protein 1 (ZBP1, also known as DAI, Figure 2). ${ }^{87-89}$ While the kinase activity of RIPK1 promotes necroptosis and apoptosis, recent evidence indicates that the 


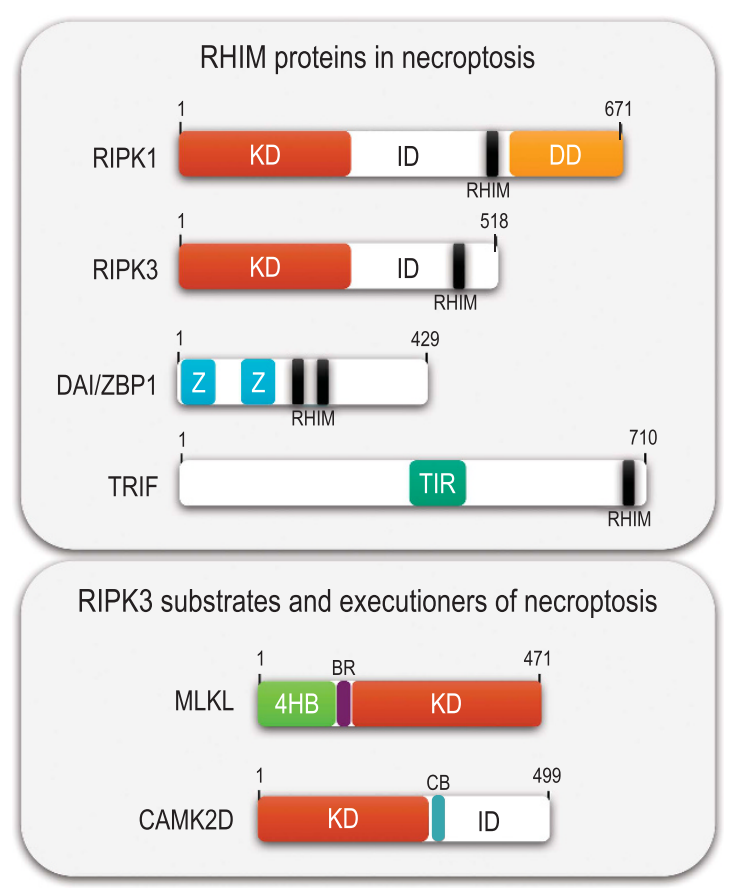

Figure 2 Domain structure of the key mediators of necroptosis. Length is indicated in number of amino acids. 4HB, four-helical bundle domain; BR, brace region; CAMK2D, calcium/calmodulin-dependent protein kinase type II subunit delta; $\mathrm{CB}$, calmodulin-binding domain; $\mathrm{DD}$, death domain; ID, intermediate domain; $\mathrm{KD}$, kinase domain; MLKL, mixed lineage kinase domain-like; RHIM, RIP homotypic interaction motif; RIPK, receptor-interacting protein kinase; TIR, Toll/interleukin receptor domain; TRIF, TIR domain-containing adaptor-inducing IFN-beta (also known as TICAM1, TIR domain-containing adapter molecule 1); ZBP1, Z-DNAbinding protein 1 (also known as DAI, DNA-dependent activator of IFN-regulatory factors)

mere binding via its RHIM domain counteracts ZBP1/DAI and RIPK3-mediated necroptosis. ${ }^{90-92}$

RIPK3 is a homologous kinase of RIPK1, with a similar $\mathrm{N}$-terminal kinase domain, and an intermediate domain that can contribute to TNF-induced activation of NF- $K B$ if overexpressed (Figure 2). RIPK3 also contains a RHIM domain at its $\mathrm{C}$-terminus, but lacks the $\mathrm{C}$-terminal death domain compared to RIPK1 ${ }^{80}$ RIPK3 kinase activity appears to be essential for necroptosis, ${ }^{18,37,38,79,93}$ although this was recently challenged by a single study demonstrating RIPK3independent activation of MLKL in a model of RIPK1dependent necroptosis (ConA-induced hepatitis). ${ }^{94}$

Another key mediator of necroptosis is MLKL, a pseudokinase, which is currently seen as the sole and main effector of necroptosis. ${ }^{16,95-101}$ MLKL possesses an N-terminal fourhelical bundle domain, which directly or indirectly results in membrane pore formation, but is kept inactive by its $\mathrm{C}$-terminal pseudokinase domain (Figure 2). ${ }^{98,99,102}$ MLKL is in many cells constitutively associated with RIPK3, through an interaction of their kinase domains. ${ }^{16}$ Phosphorylation of human RIPK3 at Ser227 is required for its interaction with MLKL. ${ }^{16}$ Interestingly, the crystal structure of MLKL bound to RIPK3 revealed that MLKL forces RIPK3 in an inactive conformation, ${ }^{16,103}$ suggesting that RIPK3 and MLKL may exist as pre-assembled non-active complexes, while the RIPK3-mediated phosphorylation may release MLKL.
Different groups reported that MLKL either has no kinase activity, ${ }^{96}$ or only a very modest kinase activity toward the artificial substrate myelin basic protein. ${ }^{95}$ In contrast to RIPK1 and RIPK3, it appears that the kinase activity of MLKL (if any) is not required for necroptosis. ${ }^{95,96}$ Phosphorylation of MLKL by kinase-active RIPK3 induces a conformational shift, which exposes the four-helical bundle domain of MLKL. ${ }^{95,96,102}$

More recently, calcium-dependent protein kinase II delta (CAMK2D) was identified as another potential substrate of RIPK3. ${ }^{104}$ RIPK3 phosphorylates CAMK2D at Thr387, which results in the activation of CAMK2D. ${ }^{104}$ Importantly, CAMK2D apparently executes necrotic cell death independently of MLKL. ${ }^{104}$ CAMK2D regulates multiple ion channels by phosphorylation, including the L-type $\mathrm{Ca}^{2+}$ channel subunit beta-2 CACNB2, ${ }^{105}$ the sarcolemmal cardiac $\mathrm{Na}^{+}$channel SCN5 $\mathrm{A}^{106}$ and the $\mathrm{K}^{+}$channel potassium channel, voltage gated Shal-related subfamily D (KCND3, also known as KV4.3). ${ }^{107}$ Activation of these channels by CAMK2D results in an influx of extracellular ions, ${ }^{105-107}$ and in the case of necrotic cell death, most likely in eventual plasma membrane rupture. Interestingly, another group reported a reverse signaling cascade in neuroblastoma cells: first cytosolic calcium accumulation and subsequent CAMK2D activation resulting in RIPK1 activation and necroptosis. ${ }^{108}$ The precise relation between CAMKs and necroptosis signaling remains to be determined.

\section{Necroptosis initiation: necrosome formation}

Canonical necrosomes: TNF-induced necroptosis is the best characterized necroptotic pathway. Upon TNF stimulation, RIPK1 and TNF receptor-associated DD (TRADD) are independently recruited to the TNF receptor by their DD domains (Figure 3a). ${ }^{109,110}$ At the TNF receptor complex (complex I), RIPK1 is ubiquitylated in its ID, allowing the recruitment of the $I_{\kappa} \mathrm{B}$ kinase complex (NEMO, IKKa and $\mathrm{IKK} \beta)^{81} \mathrm{IKK} \alpha$ - and $\mathrm{IKK} \beta$-dependent phosphorylation of RIPK1 prevents its dissociation from the receptor, and hence prevent the formation of a cytosolic pro-cell death complex (complex II). ${ }^{84,111}$ Different types of complex II can be distinguished (Ila and Ilb), depending on the composition of complex II and the activity of the proteins therein (Figure 3b). While complex Ila and IIb induce apoptosis, they can also induce necroptosis if caspase-8 is inactive or absent. ${ }^{81}$ It is still unclear whether these complexes represent different physical entities or different compositions or posttranslational regulations of essentially the same complex II. The phosphorylation and ubiquitylation of RIPK have been reviewed in detail elsewhere. ${ }^{112-115}$

Complex lla is formed after dissociation of TRADD from the TNF receptor 1 (TNFR1) and results in the recruitment of FADD, and subsequent recruitment and activation of caspase$8 .^{111,116}$ The activation of caspase-8 and subsequent induction of apoptosis is independent of RIPK1 or its kinase activity. ${ }^{81,116}$ In case cIAPs, TAK 1 or IKKa/ $\beta$ are inactive or absent, a similar complex is formed without TRADD (complex $\mathrm{Ilb}$, Figure $3 \mathrm{~b}$ ), where RIPK1 kinase activity is required for activation of caspase-8 and apoptosis. ${ }^{83,116,117}$ Hence, complex Ila formation results in RIPK1-independent apoptosis, while complex Ilb promotes RIPK1 kinase activity dependent apoptosis. $^{81}$ 
a

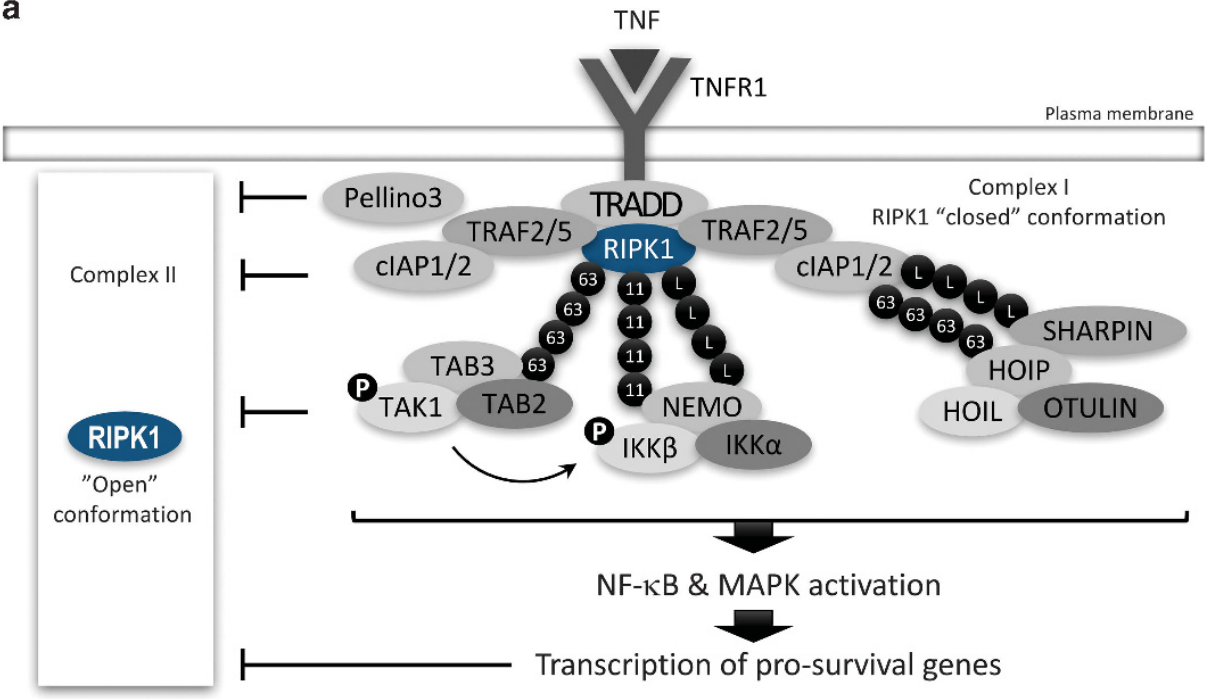

b

"Open" conformation

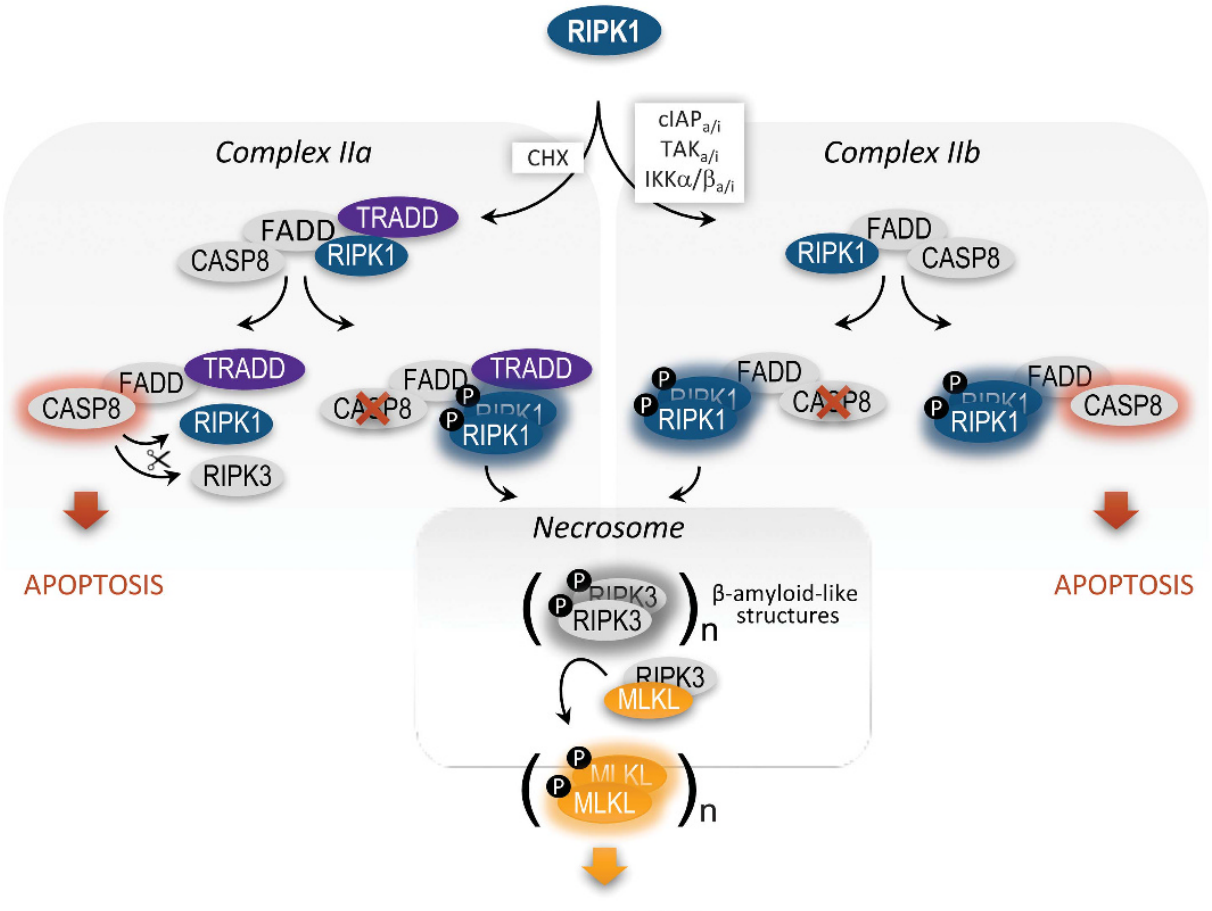

NECROPTOSIS

Figure 3 Signal transduction complexes in TNF-induced survival and cell death. (a) TNF stimulation results in formation of a receptor bound complex I, which essentially prevents cell death (see text). (b) TNF receptor dissociation of RIPK1 results in the formation of different pro-cell death complexes (complex Ila, Illb and the necrosome). Complex lla contains TRADD and can be formed independent of the scaffold and kinase function of RIPK1. In contrast, complex Ilb lacks TRADD and requires kinase-active RIPK1 for cell death induction. It is still unclear whether these complexes represent different physical entities or different compositions or post-translational regulations of essentially the same complex II. CASP, caspase; clAP, cellular inhibitor of apoptosis protein; FADD, Fas-associated protein with death domain; HOIL-1 or RBCK1, RANBP2-type and C3HC4-type zincfinger-containing 1; HOIP or RNF31, ring finger protein 31; IKK, inhibitor of NF- $\kappa B$ kinase; MLKL, mixed lineage kinase domain-like; NEMO, NF- $\kappa B$ essential modulator (sometimes misleadingly called IKK $\gamma$ since it does not possess kinase activity); NF- $\mathrm{B}$, nuclear factor kappa B; Otulin, OTU deubiquitinase with linear linkage specificity; PELI1, pellino 1; RIPK, receptor-interacting protein kinase; Sharpin, SHANK-associated RH domain-interacting protein; TAB, TAK1-binding protein; TAK1, TGF $\beta$ activated kinase 1; TNF, tumor necrosis factor; TNFR, TNF receptor; TRADD, TNF-associated death domain

When caspase-8 is absent or inactivated, kinase-active RIPK1 in complex II recruits and activates RIPK3, resulting in the formation of the necrosome (Figure $3 b$ ). The necrosome formed from complex lla consists of TRADD, RIPK1, RIPK3 and FADD, while the necrosome resulting from complex Ilb lacks TRADD. ${ }^{18,37,79}$ As a constitutive binding partner of RIPK3, MLKL is incorporated in the necrosome. ${ }^{16}$ Within the canonical necrosome, the kinase-active conformation of RIPK1 is required for the activation and autophosphorylation of RIPK3 at Ser199, ${ }^{79}$ although transphosphorylation between 


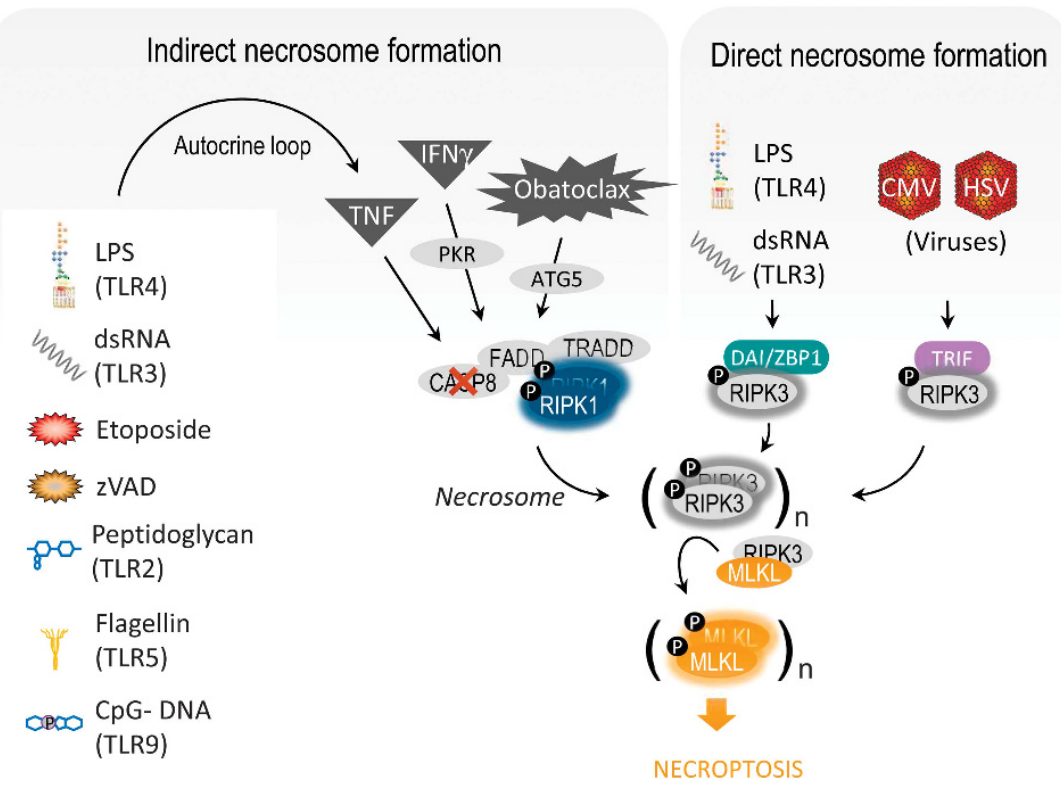

Figure 4 Direct and indirect necrosome formation by different stimuli. Many stimuli elicit necroptosis in a direct and indirect way. The direct necrosome formation involves the canonical pathway that requires RIPK1 kinase activity and the non-canonical pathway that is dependent on the TRIF adaptor or the ZBP1/DAI sensor. In the indirect way, stimuli elicit the production of TNF, which on its turn activates the canonical pathway. ATG5, autophagy related; CASP8, caspase; CMV, cytomegalovirus; FADD, Fas-associated protein with death domain; HSV, human Simian virus; IFN $\gamma$, interferon gamma; LPS, lipopolysaccharide; MLKL, mixed lineage kinase domain-like; PKR, dsRNA-activated protein kinase $\mathrm{R}$ (officially known as EIF2AK2); RIPK, receptor-interacting protein kinase; TLR, Toll-like receptor; TNF, tumor necrosis factor; TRADD, TNF-associated death domain; TRIF, officially known as Toll-like receptor adaptor molecule (TICAM); ZBP1, Z-DNA-binding protein 1 (also known as DAI); zVAD, pan-caspase inhibitor

RIPK1 and RIPK3 is most probably not required since RIPK1 is unable to phosphorylate RIPK3 in vitro. ${ }^{16,37,87,117}$ Nonetheless, during TNF-induced necroptosis, RIPK3 is phosphorylated at Ser227 in a Nec-1 inhibitable manner, ${ }^{16}$ which led to the initial (wrong) idea of transphosphorylation between RIPK1 and RIPK3. Of note, pro-necrotic ubiquitylation of RIPK1 within the necrosome is also required for maintaining its kinase activity. ${ }^{118}$

Taken together, a working model on the interaction between RIPK1 and RIPK3 emerges where inactive RIPK1 initially exists in a closed conformation at the TNFR1, where its $\mathrm{DD}$ and $\mathrm{RHIM}$ are unavailable for the formation of pro-cell death complexes. De-ubiquitylation ${ }^{119}$ and particular dephosphorylation $^{84}$ may open up RIPK1, allowing it to form a cytosolic complex II. Activation of RIPK1 by a still to be discovered mechanism then results in its autophosphorylation and activation. Depending on the availability of caspase-8, activation of RIPK1 then allows either activation of caspase-8 or RIPK3 within complex II, which results in, respectively, apoptosis or necroptosis.

Several other stimuli result in necroptosis, which depends on the kinase activity of both RIPK1 and RIPK3, and the formation of a 'canonical' RIPK1-RIPK3-MLKL-containing necrosome as described for TNF (Figure 4). These stimuli include the activation of death receptors (TNFR, Fas and TRAILR), stimulation of pathogen and Toll-like receptors (TLR2, 3, 4, 5 or 9), mitochondrial antiviral signaling protein (MAVS), retinoic acid induced gene 1 (RIG-I/DDX58), activation of the T-cell receptor and anti-cancer drugs (Obatoclax, Shikonin and Smac mimetic), vaccinia infection, and IFN or DNA damage. ${ }^{15,36-38,41,42,44,97,120-125}$ Importantly, some of these types of necroptosis are dependent on autocrine
TNF secretion and subsequent activation of RIPK1 (Figure 4). ${ }^{77,97,120,126}$ This is the case for zVAD-fmk-induced necroptosis in L929 cells, where activation of AKT and cJun $\mathrm{N}$-terminal kinase (JNK) result in TNF transcription mediated by transcription factors cJun and Sp1. ${ }^{77,120,126}$ Other examples of autocrine TNF secretion include activation of TLR2, 5 or 9 in macrophages by, respectively, peptidoglycan, flagellin or unmethylated CpG-DNA motifs in the presence of zVADfmk. Here, necroptosis depends on MyD88-dependent induction of TNF. Etoposide-induced necroptosis apparently also requires autocrine TNF secretion. ${ }^{127}$ The requirement for autocrine TNF production in etoposide-induced necroptosis suggest that RIPK1 kinase activity and canonical necrosome formation are involved. ${ }^{97}$ In conclusion, the type of necrosome formed may depend on trigger and cell type, but a key common feature is the activation of RIPK3.

Peculiar cases of 'direct' necroptosis induction have been described for IFN $\gamma$ and Obatoclax, which are able to directly activate RIPK1, without the need for autocrine TNF secretion (Figure 4). Indeed, during IFN $\gamma$-induced necroptosis, RIPK1 is activated through phosphorylation by RNA-dependent protein kinase (PKR, officially known as EIF2AK2). ${ }^{41}$ In the case of Obatoclax treatment, autophagosome formation is induced, where autophagy gene 5 (ATG5) recruits RIPK1 to assemble a RIPK1-RIPK3-FADD-containing necrosome. ${ }^{44}$

Non-canonical necrosome formation: Known exceptions to this canonical RIPK1-RIPK3 activation model are dsRNAinduced necroptosis in fibroblasts and endothelial cells, and CMV-induced necroptosis (Figure 4). CMV viral infection of primary MEF, 3T3-SA or SVEC4-10 cells results in RIPK3dependent necroptosis, which does not involve RIPK1 kinase activity, but is dependent on the sensor ZBP1/DAI. ${ }^{64}$ 
Similarly, in fibroblasts and endothelial cells, TLR3 stimulation results in RIPK3 and MLKL-dependent necroptosis, which can proceed independently of RIPK1 kinase activity, but requires the TRIF adaptor. ${ }^{97}$ Interestingly, the RIPK3 activation platform may not only depend on the stimulus, but also on the cell type. Indeed, in HaCaT cells treated with Smac mimetic and in macrophages, TLR3-induced necroptosis requires the canonical RIPK1-RIPK3 necrosome instead of the TRIF-RIPK3 necrosome. ${ }^{97,128}$ It is not known how exactly RIPK3 is activated downstream TRIF or ZBP1/DAI, but it is possible that these RHIM domain-containing proteins can function as a scaffold allowing RIPK3 recruitment, activation and autophosphorylation, as was shown for ZBP1/DAI. ${ }^{89}$ This model is supported by in vivo evidence, where the perinatal lethality of RHIM-deficient RIPK1 knock-in mice can be rescued by ZBP1/DAI deficiency, suggesting a protective role for the RIPK1 RHIM domain. Hence, ZBP1/DAI would bind and activate RIPK3, unless RIPK1 prevents this interaction by sequestering RIPK3 through homotypic RHIM-RHIM interactions. ${ }^{90-92}$

Necroptosis propagation: RIPK3 oligomerization or amyloid formation? RHIM domain-containing proteins can aggregate in amyloid-like structures. It was claimed that these amyloid fibers are essential for TNF-induced necroptosis, as they trap hyperphosphorylated RIPK1 and RIPK3 in a detergent insoluble fraction (Figure 5). ${ }^{129}$ However, the function of amyloid formation during necroptosis is still unclear. The importance of RIPK1-RIPK3 amyloid formation for necroptosis was demonstrated by mutation of the RHIM domains of RIPK1 and RIPK3, ${ }^{129}$ but this approach also prevents RIPK3 recruitment, activation and necroptosis. ${ }^{18,37,79,93,97}$ Furthermore, the protective effect of inhibitors of amyloid formation (such as Congo Red or Thioflavin T) on TNF-induced cell death was modest $(\sim 15 \%$ at $100 \mu \mathrm{M}){ }^{129}$ Hence, the protective effect of the RIPK3 RHIM mutation on necroptosis could be due to interfering with homotypic interaction between RIPK1-RIPK3, RIPK3RIPK3, TRIF-RIPK3 and ZBP1/DAI-RIPK3 interaction rather than disruption of extensive amyloid-fibril formation. Indeed, it was suggested that amyloid formation is not required for necroptosis as forced oligomerization of RIPK3 through an artificial interaction domain is sufficient for the induction of necroptosis, independent of the presence of the RHIM domain, TNF stimulation or RIPK1 activity. ${ }^{130}$ Of note, these authors specifically showed that RIPK3 oligomerization rather than dimerization is required for necroptosis, ${ }^{130}$ while another group claimed that forced dimerization of RIPK3 is sufficient for necroptosis. ${ }^{131}$ Nonetheless, necrosome formation
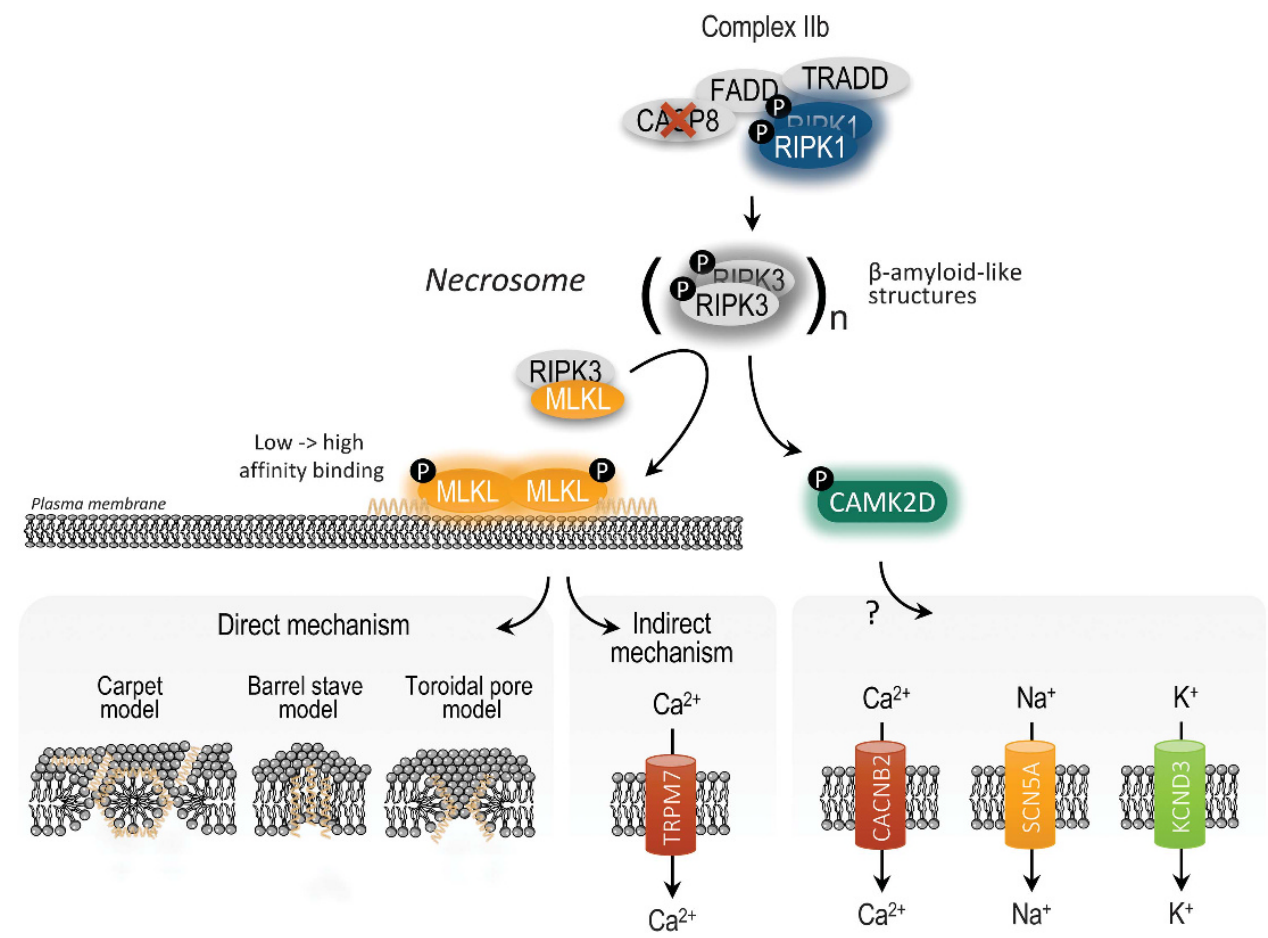

Figure 5 Necrosome formation and execution of necroptosis. RHIM-dependent necrosome formation results in phosphorylation and activation of MLKL or CAMK2 by RIPK3, which in turn activate ion influxes in the cell. MLKL is initially recruited to the plasma membrane by weak interactions with phospholipids (PIPs), but after a conformational change a second, stronger PIP interaction site is revealed in MLKL. MLKL can either directly form pores in the plasma membrane or activate ion channels, whereas CAMK2D is a known activator of several ion channels (without a currently demonstrated role in necroptosis). How MLKL induces permeabilization of the plasma membrane is unknown, but may be similar to other types of pore-forming proteins (carpet, barrel or toroidal model). 4HBD, four-helical bundle domain; CAC4NB, L-type Ca ${ }^{2+}$ channel subunit beta-2; CAMK2D, calcium-dependent protein kinase II delta; CASP, caspase; FADD, Fas-associated protein with death domain; KCND3, $\mathrm{K}^{+}$channel potassium channel, voltage gated Shal-related subfamily D; MLKL, mixed lineage kinase domain-like; RHIM, RIPK homotypic interaction motif; RIPK, receptor-interacting protein kinase; SCN5A, sarcolemmal cardiac Na ${ }^{+}$ channel; TRADD, TNF-associated death domain; TRPM7, transient receptor potential cation channel, subfamily M, member 7; ZBP1, Z-DNA-binding protein 1 (also known as DAl) 
promotes RIPK3 activation, dimer/oligo/ $\beta$ amyloid-like fiber formation and activation of MLKL.

Necroptosis execution: MLKL activation. Once activated, RIPK3 phosphorylates human MLKL at Thr357, Ser358 and Ser345, Ser347, and mouse MLKL at Thr349 and Ser352 within the MLKL activation loop. ${ }^{16,96,103}$ Phosphorylation of these residues results in an open conformational shift of MLKL and exposure of its four-helical bundle domain. ${ }^{96,102}$ How MLKL exactly executes necroptosis is still a matter of debate (Figure 5). Overexpression of the $\mathrm{N}$-terminal fourhelical bundle domain alone is sufficient to induce membrane rupture in cells. There is consensus that during necroptosis, MLKL is phosphorylated at Thr357/Ser358, leading to oligomerization through the $\mathrm{N}$-terminal domain (brace region) and translocation to the plasma membrane. ${ }^{98-100,102,132}$ However, the type of oligomers formed and the method of membrane recruitment is still under debate. Some have suggested that oligomerized MLKL can directly form a pore in the plasma membrane after binding to negatively charged phospholipids. ${ }^{98,99} \mathrm{~A}$ more advanced model was proposed, where MLKL binds to phosphorylated phosphatidylinositol phosphate (PIP) phospholipids with a low affinity site in its $\mathrm{N}$-terminal bundle domain. Conformational rearrangement of MLKL at the plasma membrane then reveals a higher affinity site for PIPs in MLKL, and results in robust plasma membrane association of MLKL and displacement of the brace domain from its four-helical bundle domain. ${ }^{133}$ These multiple interactions with phospholipids may cause different types of membrane permeabilizing mechanisms (toroidal, barrel stave and carpet, Figure 5), ${ }^{134}$ which have not been properly examined yet. In contrast, others claimed that MLKL acts as a new type of highly selective $\mathrm{Mg}^{2+}$ channel and later on oligomerizes into a less selective, larger pore. ${ }^{135}$ Yet another group found that trimerized MLKL is recruited with RIPK3 to the plasma membrane, where MLKL interacts with the kinase transient receptor potential cation channel, subfamily M, member 7 (TRPM7). In turn, the kinase/ion channel TRPM7 would be at least partially responsible for extracellular $\mathrm{Ca}^{2+}$ influx and subsequent plasma membrane damage. $^{100}$ Most recently, it was reported that MLKL tetramerizes within the necrosome, but requires further octamerization to translocate to the lipid rafts of plasma membrane, where it causes an $\mathrm{Na}^{+}$influx and cell death. ${ }^{132,136}$ Taken together, during necroptosis, phosphorylated MLKL unleashes its four-helical bundle domain, oligomerizes involving the brace domain and relocalizes to the plasma membrane, where it induces an influx of ions, either directly by channel/pore formation or indirectly through association with ion channels. Alternatively, RIPK3 may also activate CAMK2D, which in turn induces an ion influx by activating multiple ion channels, independently of $\mathrm{MLKL}^{104}$ (Figure 5).

\section{Conclusions}

Over the years, our understanding of necroptotic signaling increased substantially. It is now clear that several triggers can induce necroptosis. Furthermore, several processes (e.g., mitochondrial ROS generation) can contribute to necroptosis, but can be bypassed activating the necroptosis pathway downstream at the level of RIPK3 ${ }^{117}$ or MLKL. ${ }^{96}$ While originally RIPK1 kinase activity was a hallmark of necroptosis, recent findings indicate that RIPK3 and MLKL activation is universally required for necroptosis, both canonical and noncanonical. A core necroptotic pathway consisting of RIPK3 activation, followed by MLKL activation and membrane permeabilization has emerged. However, molecular signal transduction usually is far more complex, and the recent discovery of RIPK3- or MLKL independent necroptosis, ${ }^{94,104}$ and the unexpected function of ZBP1/DAI ${ }^{90-92}$ in the skin and thymus suggests that the necroptosis pathway did not yet yield all its secrets. And finally, to make the situation even more complex, phylogenetic analysis reveals that the necroptotic axis, except for RIPK1, is possibly poorly conserved in the animal kingdom, suggesting that completely alternative cell death mechanisms may bypass the need for necroptosis and question the universal role of necroptosis during innate immunity in the animal kingdom. ${ }^{137}$

\section{Conflict of Interest}

The authors declare no conflict of interest.

Acknowledgements. Research in the group of $\mathrm{PV}$ is supported by grants from the Vlaams Instituut voor Biotechnologie (VIB), from Ghent University (MRP, GROUPID consortium), grants from the 'Foundation against Cancer' (2012-188 and FAF-F/ 2016/865), grants from the Fonds voor Wetenschappelijk Onderzoek Vlaanderen (FWO) (FWO G.0875.11, FWO G.0A45.12N, FWO G.0787.13N, FWO G.0C37.14N and FWO G.0E04.16N), grants from the Flemish Government (Methusalem BOF09/01M00709 and BOF16/MET_V/007), and a grant from the Belgian science policy office (BELSPO)(IAP 7/32). SG was paid by the Methusalem grant and TVB has an assistant academic staff position at Ghent University.

1. Vaux DL, Korsmeyer SJ. Cell death in development. Cell 1999; 96: 245-254.

2. Glucksmann A. Cell deaths in normal vertebrate ontogeny. Biol Rev Camb Philos Soc 1951; 26: 59-86.

3. Renehan AG, Booth C, Potten CS. What is apoptosis, and why is it important? BMJ 2001; 322: $1536-1538$

4. Hanahan D, Weinberg RA. Hallmarks of cancer: the next generation. Cell 2011; 144: 646-674.

5. Manji GA, Hozak RR, LaCount DJ, Friesen PD. Baculovirus inhibitor of apoptosis functions at or upstream of the apoptotic suppressor P35 to prevent programmed cell death. $J$ Virol 1997; 71: 4509-4516.

6. Jouan-Lanhouet S, Riquet F, Duprez L, Vanden Berghe T, Takahashi N, Vandenabeele P. Necroptosis in vivo detection in experimental disease models. Semin Cell Dev Biol 2014; 35: 2-13.

7. Schweichel JU, Merker HJ. The morphology of various types of cell death in prenatal tissues. Teratology 1973; 7: 253-266.

8. Vandenabeele P, Galluzzi L, Vanden Berghe T, Kroemer G. Molecular mechanisms of necroptosis: an ordered cellular explosion. Nat Rev Mol Cell Biol 2010; 11: 700-714.

9. Kerr JF, Wyllie AH, Currie AR. Apoptosis: a basic biological phenomenon with wide-ranging implications in tissue kinetics. Br J Cancer 1972; 26: 239-257.

10. Galluzzi L, Bravo-San Pedro JM, Vitale I, Aaronson SA, Abrams JM, Adam D et al. Essential versus accessory aspects of cell death: recommendations of the NCCD 2015. Cell Death Differ 2015; 22: 58-73.

11. Krysko DV, Vanden Berghe T, D'Herde K, Vandenabeele P. Apoptosis and necrosis: detection, discrimination and phagocytosis. Methods 2008; 44: 205-221.

12. Horvitz HR, Sternberg PW, Greenwald IS, Fixsen W, Ellis HM. Mutations that affect neural cell lineages and cell fates during the development of the nematode Caenorhabditis elegans. Cold Spring Harb Symp Quant Biol 1983; 48(Pt 2): 453-463.

13. Liu X, Kim CN, Yang J, Jemmerson R, Wang X. Induction of apoptotic program in cell-free extracts: requirement for dATP and cytochrome c. Cell 1996; 86: 147-157.

14. Laster SM, Wood JG, Gooding LR. Tumor necrosis factor can induce both apoptic and necrotic forms of cell lysis. J Immunol 1988; 141: 2629-2634.

15. Degterev A, Huang Z, Boyce M, Li Y, Jagtap P, Mizushima N et al. Chemical inhibitor of nonapoptotic cell death with therapeutic potential for ischemic brain injury. Nat Chem Biol 2005; 1: 112-119. 
16. Sun L, Wang H, Wang Z, He S, Chen S, Liao D et al. Mixed lineage kinase domain-like protein mediates necrosis signaling downstream of RIP3 kinase. Cell 2012; 148: 213-227.

17. Vercammen D, Beyaert R, Denecker G, Goossens V, Van Loo G, Declercq W et al. Inhibition of caspases increases the sensitivity of L929 cells to necrosis mediated by tumor necrosis factor. J Exp Med 1998; 187: 1477-1485.

18. Zhang DW, Shao J, Lin J, Zhang N, Lu BJ, Lin SC et al. RIP3, an energy metabolism regulator that switches TNF-induced cell death from apoptosis to necrosis. Science 2009; 325: 332-336.

19. Vanden Berghe $T$, Linkermann A, Jouan-Lanhouet $S$, Walczak $H$, Vandenabeele $P$. Regulated necrosis: the expanding network of non-apoptotic cell death pathways. Nat Rev Mol Cell Biol 2014; 15: 135-147.

20. He WT, Wan H, Hu L, Chen P, Wang X, Huang Z et al. Gasdermin D is an executor of pyroptosis and required for interleukin-1beta secretion. Cell Res 2015; 25: 1285-1298.

21. David KK, Andrabi SA, Dawson TM, Dawson VL. Parthanatos, a messenger of death. Front Biosci 2009; 14: 1116-1128.

22. Dixon SJ, Lemberg KM, Lamprecht MR, Skouta R, Zaitsev EM, Gleason CE et al. Ferroptosis: an iron-dependent form of nonapoptotic cell death. Cell 2012; 149: 1060-1072.

23. Steinberg BE, Grinstein S. Unconventional roles of the NADPH oxidase: signaling, ion homeostasis, and cell death. Sci STKE 2007; 2007: pe11.

24. Rogers C, Fernandes-Alnemri T, Mayes L, Alnemri D, Cingolani G, Alnemri ES. Cleavage of DFNA5 by caspase-3 during apoptosis mediates progression to secondary necrotic/ pyroptotic cell death. Nat Commun 2017; 8: 14128.

25. Tata JR. Requirement for RNA and protein synthesis for induced regression of the tadpole tail in organ culture. Dev Biol 1966; 13: 77-94.

26. Abraham MC, Lu Y, Shaham S. A morphologically conserved nonapoptotic program promotes linker cell death in Caenorhabditis elegans. Dev Cell 2007; 12: 73-86.

27. Pilar $G$, Landmesser $L$. Ultrastructural differences during embryonic cell death in normal and peripherally deprived ciliary ganglia. J Cell Biol 1976; 68: 339-356.

28. Chu-Wang IW, Oppenheim RW. Cell death of motoneurons in the chick embryo spinal cord. I. A light and electron microscopic study of naturally occurring and induced cell loss during development. J Comp Neurol 1978; 177: 33-57.

29. Ashdown RR, Marrable AW. Adherence and fusion between the extremities of adjacent embryonic sacs in the pig. J Anat 1967; 101: 269-275.

30. Chautan M, Chazal G, Cecconi F, Gruss P, Golstein P. Interdigital cell death can occur through a necrotic and caspase-independent pathway. Curr Biol 1999; 9: 967-970.

31. Cecconi F, Alvarez-Bolado G, Meyer BI, Roth KA, Gruss P. Apaf1 (CED-4 homolog) regulates programmed cell death in mammalian development. Cell 1998; 94: 727-737.

32. Oppenheim RW, Flavell RA, Vinsant S, Prevette D, Kuan CY, Rakic P. Programmed cell death of developing mammalian neurons after genetic deletion of caspases. $J$ Neurosci 2001; 21: 4752-4760.

33. Berger SB, Kasparcova V, Hoffman S, Swift B, Dare L, Schaeffer M et al. Cutting Edge: RIP1 kinase activity is dispensable for normal development but is a key regulator of inflammation in SHARPIN-deficient mice. J Immunol 2014; 192: 5476-5480.

34. Newton K, Sun X, Dixit VM. Kinase RIP3 is dispensable for normal NF-kappa Bs, signaling by the B-cell and T-cell receptors, tumor necrosis factor receptor 1 , and Toll-like receptors 2 and 4. Mol Cell Biol 2004; 24: 1464-1469.

35. Wu J, Huang Z, Ren J, Zhang Z, He P, Li Y et al. Mlkl knockout mice demonstrate the indispensable role of Mlkl in necroptosis. Cell Res 2013; 23: 994-1006.

36. Holler N, Zaru R, Micheau O, Thome M, Attinger A, Valitutti S et al. Fas triggers an alternative, caspase-8-independent cell death pathway using the kinase RIP as effector molecule. Nat Immunol 2000; 1: 489-495.

37. Cho YS, Challa S, Moquin D, Genga R, Ray TD, Guildford M et al. Phosphorylation-driven assembly of the RIP1-RIP3 complex regulates programmed necrosis and virus-induced inflammation. Cell 2009; 137: 1112-1123.

38. He S, Liang $\mathrm{Y}$, Shao $\mathrm{F}$, Wang $\mathrm{X}$. Toll-like receptors activate programmed necrosis in macrophages through a receptor-interacting kinase-3-mediated pathway. Proc Natl Acad Sci USA 2011; 108: 20054-20059.

39. Jouan-Lanhouet S, Arshad Ml, Piquet-Pellorce C, Martin-Chouly C, Le Moigne-Muller G, Van Herreweghe $\mathrm{F}$ et al. TRAIL induces necroptosis involving RIPK1/RIPK3-dependent PARP-1 activation. Cell Death Differ 2012; 19: 2003-2014.

40. Vercammen D, Brouckaert G, Denecker G, Van de Craen M, Declercq W, Fiers W et al. Dual signaling of the Fas receptor: initiation of both apoptotic and necrotic cell death pathways. J Exp Med 1998; 188: 919-930.

41. Thapa RJ, Nogusa S, Chen P, Maki JL, Lerro A, Andrake M et al. Interferon-induced RIP1/ RIP3-mediated necrosis requires PKR and is licensed by FADD and caspases. Proc Natl Acad Sci USA 2013; 110: E3109-E3118.

42. Tenev T, Bianchi K, Darding M, Broemer M, Langlais C, Wallberg F et al. The ripoptosome, a signaling platform that assembles in response to genotoxic stress and loss of IAPs. Mol Cell 2011; 43: 432-448.

43. Saveljeva S, Mc Laughlin SL, Vandenabeele P, Samali A, Bertrand MJ. Endoplasmic reticulum stress induces ligand-independent TNFR1-mediated necroptosis in L929 cells. Cell Death Dis 2015; 6: e1587.

44. Basit F, Cristofanon S, Fulda S. Obatoclax (GX15-070) triggers necroptosis by promoting the assembly of the necrosome on autophagosomal membranes. Cell Death Differ 2013; 20: $1161-1173$.
45. Degterev A, Hitomi J, Germscheid M, Ch'en IL, Korkina O, Teng $X$ et al. Identification of RIP1 kinase as a specific cellular target of necrostatins. Nat Chem Biol 2008; 4: 313-321.

46. Oerlemans Ml, Liu J, Arslan F, den Ouden K, van Middelaar BJ, Doevendans PA et al. Inhibition of RIP1-dependent necrosis prevents adverse cardiac remodeling after myocardial ischemia-reperfusion in vivo. Basic Res Cardiol 2012; 107: 270.

47. Smith CC, Davidson SM, Lim SY, Simpkin JC, Hothersall JS, Yellon DM Necrostatin: a potentially novel cardioprotective agent? Cardiovasc Drugs Ther 2007; 21 : 227-233.

48. Duprez L, Takahashi N, Van Hauwermeiren F, Vandendriessche B, Goossens V, Vanden Berghe $\mathrm{T}$ et al. RIP kinase-dependent necrosis drives lethal systemic inflammatory response syndrome. Immunity 2011; 35: 908-918.

49. Ramachandran A, McGill MR, Xie Y, Ni HM, Ding WX, Jaeschke H. Receptor interacting protein kinase 3 is a critical early mediator of acetaminophen-induced hepatocyte necrosis in mice. Hepatology 2013; 58: 2099-2108.

50. Linkermann A, Brasen JH, Himmerkus N, Liu S, Huber TB, Kunzendorf U et al. Rip (receptor-interacting protein kinase 1) mediates necroptosis and contributes to renal ischemia/reperfusion injury. Kidney Int 2012; 81: 751-761.

51. Vandenabeele P, Grootjans S, Callewaert N, Takahashi N. Necrostatin-1 blocks both RIPK1 and IDO: consequences for the study of cell death in experimental disease models. Cell Death Differ 2013; 20: 185-187.

52. Takahashi N, Duprez L, Grootjans S, Cauwels A, Nerinckx W, DuHadaway JB et al. Necrostatin-1 analogues: critical issues on the specificity, activity and in vivo use in experimental disease models. Cell Death Dis 2012; 3: e437.

53. Linkermann A, Brasen JH, De Zen F, Weinlich R, Schwendener RA, Green DR et al. Dichotomy between RIP1- and RIP3-mediated necroptosis in tumor necrosis factor-alphainduced shock. Mol Med 2012; 18: 577-586.

54. Prendergast GC, Metz R, Muller AJ. Towards a genetic definition of cancer-associated inflammation: role of the IDO pathway. Am J Pathol 2010; 176: 2082-2087.

55. Linkermann A, Brasen JH, Darding M, Jin MK, Sanz AB, Heller JO et al. Two independent pathways of regulated necrosis mediate ischemia-reperfusion injury. Proc Natl Acad Sci USA 2013; 110: 12024-12029.

56. Newton K, Dugger DL, Wickliffe KE, Kapoor N, de Almagro MC, Vucic D et al. Activity of protein kinase RIPK3 determines whether cells die by necroptosis or apoptosis. Science 2014; 343: 1357-1360

57. Meng L, Jin W, Wang X. RIP3-mediated necrotic cell death accelerates systematic inflammation and mortality. Proc Natl Acad Sci USA 2015; 112: 11007-11012.

58. Murakami Y, Matsumoto H, Roh M, Giani A, Kataoka K, Morizane $\mathrm{Y}$ et al. Programmed necrosis, not apoptosis, is a key mediator of cell loss and DAMP-mediated inflammation in dsRNA-induced retinal degeneration. Cell Death Differ 2014; 21: 270-277.

59. Roychowdhury S, McMullen MR, Pisano SG, Liu X, Nagy LE. Absence of receptor interacting protein kinase 3 prevents ethanol-induced liver injury. Hepatology 2013; 57 1773-1783.

60. Newton K, Dugger DL, Maltzman A, Greve JM, Hedehus M, Martin-McNulty B et al. RIPK3 deficiency or catalytically inactive RIPK1 provides greater benefit than MLKL deficiency in mouse models of inflammation and tissue injury. Cell Death Differ 2016; 23: 1565-1576.

61. Moriwaki K, Balaji S, McQuade T, Malhotra N, Kang J, Chan FK. The necroptosis adaptor RIPK3 promotes injury-induced cytokine expression and tissue repair. Immunity 2014; 41 567-578.

62. Polykratis A, Hermance N, Zelic M, Roderick J, Kim C, Van TM et al. Cutting edge: RIPK1 Kinase inactive mice are viable and protected from TNF-induced necroptosis in vivo. J Immunol 2014; 193: 1539-1543.

63. Upton JW, Kaiser WJ, Mocarski ES. Cytomegalovirus M45 cell death suppression requires receptor-interacting protein $(\mathrm{RIP})$ homotypic interaction motif $(\mathrm{RHIM})$-dependent interaction with RIP1. J Biol Chem 2008; 283: 16966-16970.

64. Upton JW, Kaiser WJ, Mocarski ES. Virus inhibition of RIP3-dependent necrosis. Cell Host Microbe 2010; 7 : 302-313.

65. Guo H, Kaiser WJ, Mocarski ES. Manipulation of apoptosis and necroptosis signaling by herpesviruses. Med Microbiol Immunol 2015; 204: 439-448.

66. Pearson JS, Giogha C, Muhlen S, Nachbur U, Pham CL, Zhang Y et al. EspL is a bacteria cysteine protease effector that cleaves RHIM proteins to block necroptosis and inflammation. Nat Microbiol 2017; 2: 16258.

67. Lawlor KE, Khan N, Mildenhall A, Gerlic M, Croker BA, D'Cruz AA et al. RIPK3 promotes cell death and NLRP3 inflammasome activation in the absence of MLKL. Nat Commun 2015; 6: 6282.

68. Conos SA, Chen KW, De Nardo D, Hara H, Whitehead L, Nunez G et al. Active MLKL triggers the NLRP3 inflammasome in a cell-intrinsic manner. Proc Natl Acad Sci USA 2017; 114: E961-E969.

69. Gutierrez KD, Davis MA, Daniels BP, Olsen TM, Ralli-Jain P, Tait SWG et al. MLKL activation triggers NLRP3-mediated processing and release of IL-1 $\beta$ independently of gasdermin-D. J Immunol 2017; 198: 2156-2164.

70. Kang S, Fernandes-Alnemri T, Rogers C, Mayes L, Wang Y, Dillon C et al. Caspase-8 scaffolding function and MLKL regulate NLRP3 inflammasome activation downstream of TLR3. Nat Commun 2015; 6: 7515 .

71. Man SM, Kanneganti TD. Converging roles of caspases in inflammasome activation, cell death and innate immunity. Nat Rev Immunol 2016; 16: 7-21. 
72. Shlomovitz I, Zargrian S, Gerlic M. Mechanisms of RIPK3-induced inflammation. Immunol Cell Biol 2017; 95: 166-172.

73. Kearney CJ, Cullen SP, Tynan GA, Henry CM, Clancy D, Lavelle EC et al. Necroptosis suppresses inflammation via termination of TNF- or LPS-induced cytokine and chemokine production. Cell Death Differ 2015; 22: 1313-1327.

74. Yatim N, Jusforgues-Saklani H, Orozco S, Schulz O, Barreira da Silva R, Reis e Sousa C et al. RIPK1 and NF-kappaB signaling in dying cells determines cross-priming of CD8(+) T cells. Science 2015; 350: 328-334.

75. Yoon S, Bogdanov K, Kovalenko A, Wallach D. Necroptosis is preceded by nuclear translocation of the signaling proteins that induce it. Cell Death Differ 2015; 23: 253-260.

76. Chen W, Wu J, Li L, Zhang Z, Ren J, Liang Y et al. Ppm1b negatively regulates necroptosis through dephosphorylating Rip3. Nat Cell Biol 2015; 17: 434-444.

77. Christofferson DE, Li Y, Hitomi J, Zhou W, Upperman C, Zhu H et al. A novel role for RIP1 kinase in mediating TNFalpha production. Cell Death Dis 2012; 3: e320.

78. Wang J, Huo K, Ma L, Tang L, Li D, Huang $X$ et al. Toward an understanding of the protein interaction network of the human liver. Mol Syst Biol 2011; 7: 536.

79. He S, Wang L, Miao L, Wang T, Du F, Zhao L et al. Receptor interacting protein kinase-3 determines cellular necrotic response to TNF-alpha. Cell 2009; 137: $1100-1111$.

80. Festjens N, Vanden Berghe T, Cornelis S, Vandenabeele P. RIP1, a kinase on the crossroads of a cell's decision to live or die. Cell Death Differ 2007; 14: 400-410.

81. Pasparakis M, Vandenabeele P. Necroptosis and its role in inflammation. Nature 2015; 517: 311-320.

82. Chan FK, Luz NF, Moriwaki K. Programmed necrosis in the cross talk of cell death and inflammation. Annu Rev Immunol 2015; 33: 79-106.

83. Dondelinger Y, Aguileta MA, Goossens V, Dubuisson C, Grootjans S, Dejardin E et al. RIPK3 contributes to TNFR1-mediated RIPK1 kinase-dependent apoptosis in conditions of CIAP1/2 depletion or TAK1 kinase inhibition. Cell Death Differ 2013; 20: 1381-1392.

84. Dondelinger $Y$, Jouan-Lanhouet S, Divert T, Theatre E, Bertin J, Gough PJ et al. NF-kappaB-independent role of IKKalpha/IKKbeta in preventing RIPK1 kinase-dependent apoptotic and necroptotic cell death during TNF signaling. Mol Cell 2015; 60: 63-76.

85. Chen D, Li X, Zhai Z, Shu HB. A novel zinc finger protein interacts with receptor-interacting protein (RIP) and inhibits tumor necrosis factor (TNF)- and IL1-induced NF-kappa B activation. J Biol Chem 2002; 277: 15985-15991.

86. Boldin MP, Goncharov TM, Goltsev YV, Wallach D. Involvement of MACH, a novel MORT1/ FADD-interacting protease, in Fas/APO-1- and TNF receptor-induced cell death. Cell 1996; 85: 803-815.

87. Sun X, Yin J, Starovasnik MA, Fairbrother WJ, Dixit VM. Identification of a novel homotypic interaction motif required for the phosphorylation of receptor-interacting protein (RIP) by RIP3. J Biol Chem 2002; 277: 9505-9511.

88. Kaiser WJ, Offermann MK. Apoptosis induced by the toll-like receptor adaptor TRIF is dependent on its receptor interacting protein homotypic interaction motif. J Immunol 2005 174: $4942-4952$.

89. Rebsamen M, Heinz LX, Meylan E, Michallet MC, Schroder K, Hofmann K et al. DAI/ZBP1 recruits RIP1 and RIP3 through RIP homotypic interaction motifs to activate NF-kappaB. EMBO Rep 2009; 10: 916-922.

90. Lin J, Kumari S, Kim C, Van TM, Wachsmuth L, Polykratis A et al. RIPK1 counteracts ZBP1mediated necroptosis to inhibit inflammation. Nature 2016; 540: 124-128.

91. Newton K, Wickliffe KE, Maltzman A, Dugger DL, Strasser A, Pham VC et al. RIPK1 inhibits ZBP1-driven necroptosis during development. Nature 2016; 540: 129-133.

92. Vanden Berghe T, Kaiser WJ. RIPK1 prevents aberrant ZBP1-initiated necroptosis. Oncotarget 2017; 8: 1-2.

93. Upton JW, Kaiser WJ, Mocarski ES. DAI/ZBP1/DLM-1 complexes with RIP3 to mediate virus-induced programmed necrosis that is targeted by murine cytomegalovirus vIRA. Cell Host Microbe 2012; 11: 290-297.

94. Gunther C, He GW, Kremer AE, Murphy JM, Petrie EJ, Amann K et al. The pseudokinase MLKL mediates programmed hepatocellular necrosis independently of RIPK3 during hepatitis. J Clin Invest 2016; 126: 4346-4360.

95. Zhao J, Jitkaew S, Cai Z, Choksi S, Li Q, Luo J et al. Mixed lineage kinase domain-like is a key receptor interacting protein 3 downstream component of TNF-induced necrosis. Proc Natl Acad Sci USA 2012; 109: 5322-5327.

96. Murphy JM, Czabotar PE, Hildebrand JM, Lucet IS, Zhang JG, Alvarez-Diaz S et al. The pseudokinase MLKL mediates necroptosis via a molecular switch mechanism. Immunity 2013; 39: 443-453.

97. Kaiser WJ, Sridharan H, Huang C, Mandal P, Upton JW, Gough PJ et al. Toll-like receptor 3-mediated necrosis via TRIF, RIP3, and MLKL. J Biol Chem 2013; 288: 31268-31279.

98. Dondelinger Y, Declercq W, Montessuit S, Roelandt R, Goncalves A, Bruggeman I et al. MLKL compromises plasma membrane integrity by binding to phosphatidylinositol phosphates. Cell Rep 2014; 7: 971-981.

99. Wang H, Sun L, Su L, Rizo J, Liu L, Wang LF et al. Mixed lineage kinase domain-like protein MLKL causes necrotic membrane disruption upon phosphorylation by RIP3. Mol Cell 2014; 54: 133-146.

100. Cai Z, Jitkaew S, Zhao J, Chiang HC, Choksi S, Liu J et al. Plasma membrane translocation of trimerized MLKL protein is required for TNF-induced necroptosis. Nat Cell Biol 2014; 16 : $55-65$.
101. Chen X, Li W, Ren J, Huang D, He WT, Song Y et al. Translocation of mixed lineage kinase domain-like protein to plasma membrane leads to necrotic cell death. Cell Res 2014; 24 : 105-121.

102. Hildebrand JM, Tanzer MC, Lucet IS, Young SN, Spall SK, Sharma P et al. Activation of the pseudokinase MLKL unleashes the four-helix bundle domain to induce membrane localization and necroptotic cell death. Proc Natl Acad Sci USA 2014; 111: 15072-15077.

103. Xie T, Peng W, Yan C, Wu J, Gong X, Shi Y. Structural insights into RIP3-mediated necroptotic signaling. Cell Rep 2013; 5: 70-78.

104. Zhang T, Zhang Y, Cui M, Jin L, Wang Y, Lv F et al. CaMKII is a RIP3 substrate mediating ischemia- and oxidative stress-induced myocardial necroptosis. Nat Med 2016; 22: $175-182$.

105. Koval OM, Guan X, Wu Y, Joiner ML, Gao Z, Chen B et al. CaV1.2 beta-subunit coordinates CaMKII-triggered cardiomyocyte death and after depolarizations. Proc Natl Acad Sci USA 2010; 107: 4996-5000.

106. Ashpole NM, Herren AW, Ginsburg KS, Brogan JD, Johnson DE, Cummins TR et al. Ca2 +/calmodulin-dependent protein kinase II (CaMKII) regulates cardiac sodium channel NaV1.5 gating by multiple phosphorylation sites. J Biol Chem 2012; 287: 19856-19869.

107. Sergeant GP, Ohya S, Reihill JA, Perrino BA, Amberg GC, Imaizumi $Y$ et al. Regulation of Kv4.3 currents by $\mathrm{Ca2+/calmodulin-dependent} \mathrm{protein} \mathrm{kinase} \mathrm{II.} \mathrm{Am} \mathrm{J} \mathrm{Physiol} \mathrm{Cell} \mathrm{Physiol}$ 2005; 288: C304-C313.

108. Nomura M, Ueno A, Saga K, Fukuzawa M, Kaneda Y. Accumulation of cytosolic calcium induces necroptotic cell death in human neuroblastoma. Cancer Res 2014; 74: 1056-1066.

109. Hsu H, Shu HB, Pan MG, Goeddel DV. TRADD-TRAF2 and TRADD-FADD interactions define two distinct TNF receptor 1 signal transduction pathways. Cell 1996; 84: 299-308.

110. Zheng L, Bidere N, Staudt D, Cubre A, Orenstein J, Chan FK et al. Competitive control of independent programs of tumor necrosis factor receptor-induced cell death by TRADD and RIP1. Mol Cell Biol 2006; 26: 3505-3513.

111. Micheau O, Tschopp J. Induction of TNF receptor I-mediated apoptosis via two sequential signaling complexes. Cell 2003; 114: 181-190.

112. Dondelinger $Y$, Vandenabeele $P$, Bertrand MJ. Regulation of RIPK1's cell death function by phosphorylation. Cell Cycle 2016; 15: 5-6.

113. Dondelinger $Y$, Darding M, Bertrand MJ, Walczak H. Poly-ubiquitination in TNFR1mediated necroptosis. Cell Mol Life Sci 2016; 73: 2165-2176.

114. Silke J, Vince J. IAPs and cell death. Curr Top Microbiol Immunol 2017; 403: 95-117.

115. Varfolomeev E, Vucic D. Intracellular regulation of TNF activity in health and disease. Cytokine 2016; pii: S1043-4666(16)30489-6.

116. Wang $L$, Du F, Wang $X$. TNF-alpha induces two distinct caspase-8 activation pathways. Cell 2008; 133: 693-703.

117. McQuade T, Cho Y, Chan FK. Positive and negative phosphorylation regulates RIP1- and RIP3-induced programmed necrosis. Biochem J 2013; 456: 409-415.

118. de Almagro MC, Goncharov T, Izrael-Tomasevic A, Duttler S, Kist M, Varfolomeev E et al. Coordinated ubiquitination and phosphorylation of RIP1 regulates necroptotic cell death. Cell Death Differ 2017; 24: 26-37.

119. Liu X, Shi F, Li Y, Yu X, Peng S, Li W et al. Post-translational modifications as key regulators of TNF-induced necroptosis. Cell Death Dis 2016; 7: e2293.

120. Hitomi J, Christofferson DE, Ng A, Yao J, Degterev A, Xavier RJ et al. Identification of a molecular signaling network that regulates a cellular necrotic cell death pathway. Cell 2008; 135: 1311-1323.

121. Han W, Li L, Qiu S, Lu Q, Pan Q, Gu Y et al. Shikonin circumvents cancer drug resistance by induction of a necroptotic death. Mol Cancer Ther 2007; 6: 1641-1649.

122. Ch'en IL, Beisner DR, Degterev A, Lynch C, Yuan J, Hoffmann A et al. Antigen-mediated T cell expansion regulated by parallel pathways of death. Proc Natl Acad Sci USA 2008; 105 : 17463-17468.

123. Thapa RJ, Basagoudanavar SH, Nogusa S, Irrinki K, Mallilankaraman K, Slifker MJ et al. NF-kappaB protects cells from gamma interferon-induced RIP1-dependent necroptosis. Mol Cell Biol 2011; 31: 2934-2946.

124. Rajput A, Kovalenko A, Bogdanov K, Yang SH, Kang TB, Kim JC et al. RIG-I RNA helicase activation of IRF3 transcription factor is negatively regulated by caspase-8-mediated cleavage of the RIP1 protein. Immunity 2011; 34: 340-351.

125. McComb S, Cessford E, Alturki NA, Joseph J, Shutinoski B, Startek JB et al. Type-I interferon signaling through ISGF3 complex is required for sustained Rip3 activation and necroptosis in macrophages. Proc Natl Acad Sci USA 2014; 111: E3206-E3213.

126. McNamara CR, Ahuja R, Osafo-Addo AD, Barrows D, Kettenbach A, Skidan I et al. Akt regulates TNFalpha synthesis downstream of RIP1 kinase activation during necroptosis. PLOS ONE 2013; 8: e56576.

127. Biton S, Ashkenazi A. NEMO and RIP1 control cell fate in response to extensive DNA damage via TNF-alpha feedforward signaling. Cell 2011; 145: 92-103.

128. Feoktistova M, Geserick P, Kellert B, Dimitrova DP, Langlais C, Hupe M et al. clAPs block ripoptosome formation, a RIP1/caspase-8 containing intracellular cell death complex differentially regulated by cFLIP isoforms. Mol Cell 2011; 43: 449-463.

129. Li J, McQuade T, Siemer AB, Napetschnig J, Moriwaki K, Hsiao YS et al. The RIP1/RIP3 necrosome forms a functional amyloid signaling complex required for programmed necrosis. Cell 2012; 150: 339-350.

130. Orozco S, Yatim N, Werner MR, Tran H, Gunja SY, Tait SW et al. RIPK1 both positively and negatively regulates RIPK3 oligomerization and necroptosis. Cell Death Differ 2014; 21: 1511-1521. 
131. Wu XN, Yang ZH, Wang XK, Zhang Y, Wan H, Song Y et al. Distinct roles of RIP1-RIP3 hetero- and RIP3-RIP3 homo-interaction in mediating necroptosis. Cell Death Differ 2014; 21: $1709-1720$

132. Chen W, Zhou Z, Li L, Zhong CQ, Zheng X, Wu X et al. Diverse sequence determinants control human and mouse receptor interacting protein 3 (RIP3) and mixed lineage kinase domain-like (MLKL) interaction in necroptotic signaling. J Biol Chem 2013; 288: 16247-16261.

133. Quarato G, Guy CS, Grace CR, Llambi F, Nourse A, Rodriguez DA et al. Sequential engagement of distinct MLKL phosphatidylinositol-binding sites executes necroptosis. Mol Cell 2016; 61: 589-601.

134. Melo MN, Ferre R, Castanho MA. Antimicrobial peptides: linking partition, activity and high membrane-bound concentrations. Nat Rev Microbiol 2009; 7: 245-250.

135. Xia B, Fang S, Chen X, Hu H, Chen P, Wang H et al. MLKL forms cation channels. Cell Res 2016; 26: 517-528.

136. Huang D, Zheng X, Wang ZA, Chen X, He WT, Zhang $Y$ et al. MLKL channel in necroptosis is octamer formed by tetramers in a dyadic process. Mol Cell Biol 2017 37(5): pii: e00497-16.

137. Dondelinger Y, Hulpiau P, Saeys Y, Bertrand MJ, Vandenabeele P. An evolutionary perspective on the necroptotic pathway. Trends Cell Biol 2016; 26: 721-732.

138. He L, Peng K, Liu Y, Xiong J, Zhu FF. Low expression of mixed lineage kinase domain-like protein is associated with poor prognosis in ovarian cancer patients. Onco Targets Ther 2013; 6: 1539-1543.

139. Pierdomenico M, Negroni A, Stronati L, Vitali R, Prete E, Bertin J et al. Necroptosis is active in children with inflammatory bowel disease and contributes to heighten intestinal inflammation. Am J Gastroenterol 2014; 109: 279-287.

140. Mizumura K, Cloonan SM, Nakahira K, Bhashyam AR, Cervo M, Kitada T et al. Mitophagydependent necroptosis contributes to the pathogenesis of COPD. J Clin Invest 2014; 124: $3987-4003$.

141. Ofengeim $D$, Ito $Y$, Najafov $A, Z$ Zhang $Y$, Shan $B$, DeWitt JP et al. Activation of necroptosis in multiple sclerosis. Cell Rep 2015; 10: 1836-1849.
142. Koo GB, Morgan MJ, Lee DG, Kim WJ, Yoon JH, Koo JS et al. Methylation-dependent loss of RIP3 expression in cancer represses programmed necrosis in response to chemotherapeutics. Cell Res 2015; 25: 707-725.

143. Geserick P, Wang J, Schilling R, Horn S, Harris PA, Bertin J et al. Absence of RIPK3 predicts necroptosis resistance in malignant melanoma. Cell Death Dis 2015; 6 : e1884.

144. Gaiha GD, McKim KJ, Woods M, Pertel T, Rohrbach J, Barteneva N et al. Dysfunctional HIV-specific CD8+ T cell proliferation is associated with increased caspase-8 activity and mediated by necroptosis. Immunity 2014; 41: 1001-1012.

145. Moriwaki K, Bertin J, Gough PJ, Orlowski GM, Chan FK. Differential roles of RIPK1 and RIPK3 in TNF-induced necroptosis and chemotherapeutic agent-induced cell death. Cell Death Dis 2015; 6: e1636.

146. Fukasawa M, Kimura M, Morita S, Matsubara K, Yamanaka S, Endo C et al. Microarray analysis of promoter methylation in lung cancers. J Hum Genet 2006; 51: 368-374.

147. Cerhan JR, Ansell SM, Fredericksen ZS, Kay NE, Liebow M, Call TG et al. Genetic variation in 1253 immune and inflammation genes and risk of non-Hodgkin lymphoma. Blood 2007; 110: 4455-4463.

148. Colbert LE, Fisher SB, Hardy CW, Hall WA, Saka B, Shelton JW et al. Pronecrotic mixed lineage kinase domain-like protein expression is a prognostic biomarker in patients with early-stage resected pancreatic adenocarcinoma. Cancer 2013; 119: 3148-3155.

149. Ertao Z, Jianhui C, Kang W, Zhijun Y, Hui W, Chuangqi $C$ et al. Prognostic value of mixed lineage kinase domain-like protein expression in the survival of patients with gastric caner. Tumour Biol 2016; 37: 13679-13685.

150. Ruan JY, Mei L, Zhu Q, Shi G, Wang H. Mixed lineage kinase domain-like protein is a prognostic biomarker for cervical squamous cell cancer. Int J Clin Exp Pathol 2015; 8 : 15035-15038.

151. Kim SK, Kim WJ, Yoon JH, Ji JH, Morgan MJ, Cho H et al. Upregulated RIP3 expression potentiates MLKL phosphorylation-mediated programmed necrosis in toxic epidermal necrolysis. J Invest Dermatol 2015; 135: 2021-2030.

152. Nugues AL, El Bouazzati H, Hetuin D, Berthon C, Loyens A, Bertrand E et al. RIP3 is downregulated in human myeloid leukemia cells and modulates apoptosis and caspasemediated p65/RelA cleavage. Cell Death Dis 2014; 5: e1384.

Supplementary Information accompanies this paper on Cell Death and Differentiation website (http://www.nature.com/cdd) 